\title{
Oficina de Jogos Teatrais
}

Karla Elisa Armellini

e009039a@educacao.sp.gov.br

E.E.Prof. Antonio Nascimento - São Bernardo do Campo - SP - Brasil

\section{Resumo}

Uma análise mais aprofundada sobre a E.E. Prof. Antonio Nascimento indica a existência de problemas que necessitam de tratamento pontual para que a escola apresente aumento nos índices do IDEB como também nos índices do SARESP. Além da preocupação com as metas estabelecidas em nivel federal e estadual, outro indicador demonstra a necessidade de ações imediatas: o índice de abandono e retenção apresentados pela escola, tanto no Ensino Fundamental como no Ensino Médio. Dessa forma, torna-se clara que a escola está sendo ineficiente na sua proposta de oferecer educação de qualidade. A "Oficina de Jogos Teatrais" traz como proposta trabalhar a competência leitora e escritora, através de diferentes leituras e discussões acerca dos temas escolhidos e/ou propostos, buscando relaciona-los com a realidade em que os alunos estão inseridos, desenvolvendo habilidades que não haviam sido adquiridas até então e dando significado ao aprendizado e à escola.

Os objetivos estão diretamente vinculados ao alcance das metas oficiais estabelecidas, à redução do índice de retenção no $9^{\circ}$ ano e nas séries do Ensino Médio e à redução do absenteísmo para garantir aumento no fluxo, um dos fatores computados para o calculo do IDESP.

Para tanto, o valor solicitado através do Edital $n^{011}$, que totaliza $R \$ 93.030,00$ será utilizado em melhorias de infraestrutura, contratação de profissionais capacitados a desenvolverem as "Oficinas", aquisição de materiais permanentes e de consumo para as diferentes etapas do projeto. A escola oferece como contrapartida 0 trabalho dos profissionais da sua equipe gestora e a estrutura física adequada às necessidades do projeto.

Palavras-chaves: Plano de Empreendimento. Jogos teatrais. Leitura e escrita. Gestão empreendedora na Educação. 


\section{Caracterização da Escola}

A Escola Estadual Prof. Antonio Nascimento, localizada em Jordanópolis - São Bernardo do Campo (SP), foi fundado em 1968 e atende ao Ensino Fundamental II e ao Ensino Médio Regular. A escola tem como missão "ser uma escola reconhecidamente excelente na oferta de ensino de qualidade, apoiada nos resultados obtidos em avaliações internas e externas e, que contribua para a formação de jovens cidadãos éticos, comprometidos com o desenvolvimento da sociedade em que vivem e preparados para o mundo do trabalho." e a visão de "ser referência em qualidade no processo ensino aprendizagem no município, reconhecida como escola de excelência na formação educacional de crianças e jovens, capazes de atuar de maneira humana e ética em todos os segmentos da sociedade.".

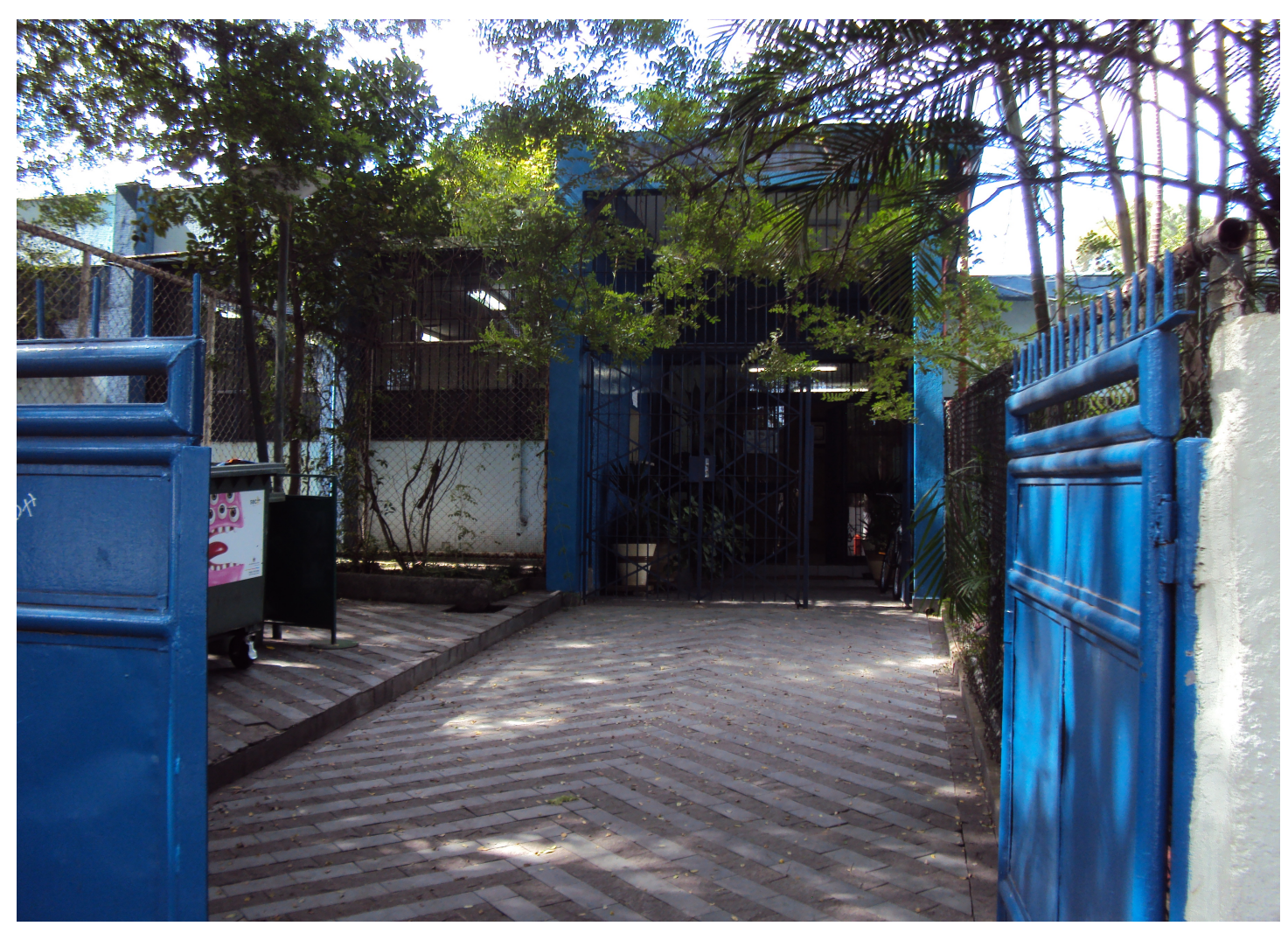

\section{Instalações}

A E.E.Prof. Antonio Nascimento foi fundada no ano de 1968. Apresenta área superior à $4.000 \mathrm{~m}^{2}$. São dois prédios distintos, ambos com andar térreo e $1^{\circ}$ andar, com quatro salas em cada andar. São quinze salas de aula, um laboratório de ciências, um laboratório de informática, uma sala de vídeo, uma biblioteca, uma quadra coberta de dimensões oficiais, uma quadra descoberta, um refeitório, uma cantina licitada e jardins. Apesar de se tratar de uma escola antiga, de maneira geral os espaços são bem conservados. Temos problemas com a estrutura do telhado, mas há previsão de reforma pela SEE-SP para o ano de 2016.

\section{Breve histórico}

O quadro a seguir apresenta a relação dos acontecimentos mais relevantes para a evolução da escola, desde a fundação até hoje. 
Oficina de Jogos Teatrais

\begin{tabular}{|l|l|}
\hline Ano & Acontecimentos relevantes \\
\hline 1968 & Fundação da escola \\
\hline 1975 & Passou a E.E.P.G \\
\hline 1984 & Passou a atender o Ensino Médio \\
\hline 1984 & Passa a E.E.P.S.G \\
\hline 1994 & Deixou de atender o Ensino Fundamental - Ciclo I \\
\hline 1998 & Passou E.E.Prof. Antonio Nascimento \\
\hline 1998 & Construção da cobertura da Quadra \\
\hline 2003 & Aposentadoria do Diretor da Escola por 23 anos \\
\hline 2005 & Posse da atual Diretora da Escola \\
\hline 2008 & Encerramento do EJA no período noturno \\
\hline 2009 & Reforma da Quadra com nova cobertura \\
\hline 2011 & Encerramento da atividades no período noturno \\
\hline 2012 & Parceria com a empresa ZF Sachs \\
\hline 2015 & Reformulação da equipe gestora \\
\hline
\end{tabular}

\section{Professores e funcionários}

A equipe é formada por 34 professores, distribuídos da seguinte forma:

\begin{tabular}{|l|l|}
\hline Disciplina / Área & Quant. de professores \\
\hline Língua Portuguesa & 07 \\
\hline Matemática & 05 \\
\hline Ciências & 03 \\
\hline Biologia & 01 \\
\hline Química & 01 \\
\hline Física & 02 \\
\hline Inglês & 02 \\
\hline Geografia & 03 \\
\hline História & 03 \\
\hline Sociologia & 01 \\
\hline Filosofia & 02 \\
\hline Educação Física & 03 \\
\hline Artes & 01 \\
\hline
\end{tabular}


Do total de professores, 21 são efetivos, 02 são readaptados e 03 são categoria $F$ (com estabilidade, mesmo não sendo efetivos). Todos os outros são categoria $O$, ou seja, tem contrato de trabalho por tempo determinado. Todos são graduados. Uma professora tem o título de Mestre, 05 são pós-graduados e 02 são pós-graduandos.

Além disso, a escola conta com 11 funcionários de apoio, sendo 07 Agentes de Organização Escolar, que desempenham suas funções na secretaria ou no pátio, como inspetores de alunos, uma merendeira terceirizada e três funcionárias de limpeza, também terceirizadas.

\section{Perfil dos alunos}

Os alunos estão distribuídos por séries e turnos da seguinte maneira:

\begin{tabular}{|c|c|c|c|c|c|c|}
\hline \multirow[b]{2}{*}{ Série/Ano } & \multirow{2}{*}{$\begin{array}{l}\text { Média } \\
\text { de } \\
\text { idade }\end{array}$} & \multirow{2}{*}{$\begin{array}{l}\text { Total } \\
\text { de } \\
\text { alunos }\end{array}$} & \multicolumn{2}{|l|}{ Manhã } & \multicolumn{2}{|l|}{ Tarde } \\
\hline & & & $\begin{array}{l}\mathrm{N}^{0} \\
\text { alunos }\end{array}$ & $\begin{array}{l}\mathrm{N}^{0} \\
\text { turmas }\end{array}$ & $\begin{array}{l}\mathrm{N}^{0} \\
\text { alunos }\end{array}$ & $\begin{array}{l}\mathrm{N}^{0} \\
\text { turmas }\end{array}$ \\
\hline $6^{\circ}$ ano & 11,5 & 86 & - & & 86 & 3 \\
\hline $7^{\circ}$ ano & 12 & 70 & - & & 70 & 2 \\
\hline $8^{\circ}$ ano & 13,5 & 102 & - & & 102 & 3 \\
\hline $9^{\circ}$ ano & 14,6 & 106 & - & & 106 & 4 \\
\hline $1^{10}$ E.M. & 15,7 & 118 & 118 & 4 & - & \\
\hline $2^{0}$ E.M. & 16,6 & 69 & 69 & 2 & - & \\
\hline $3^{\circ}$ E.M. & 17,4 & 61 & 61 & 2 & - & \\
\hline TOTAL & - & 612 & 248 & 08 & 364 & 12 \\
\hline
\end{tabular}

Nossa clientela é constituída de forma bastante heterogênea, pois atendemos alunos moradores do bairro onde estamos inseridos, porém também atendemos crianças e adolescentes provenientes de duas comunidades pertencentes ao município vizinho, Diadema. Sendo assim, uma parte dos alunos mora distante da escola. As diferenças sociais são evidentes e muitas vezes implicam em situações conflituosas dentro da escola.

Podemos afirmar que as atividades propostas pela escola são bem aceitas pelos alunos, principalmente as de aspecto pedagógicos, como mostras culturais ou participações em feiras de ciência e tecnologia.

Temos um pequeno número de alunos que trabalham ou que fazem estágios remunerados, sendo que quase a totalidade está matriculado no $3^{\circ}$ ano do Ensino Médio. Os problemas disciplinares existem, mas são pontuais e na grande maioria das vezes estão relacionados a problemas de aprendizagem. Infelizmente a participação dos pais na vida escolar dos alunos vem diminuindo a cada ano e ao atingir o Ensino Médio, a redução da presença dos pais se acentua muito.

\section{Características do entorno}

A escola está inserida num bairro que se formou quando da chegada das empresas automobilísticas em SBC e, inicialmente, foi constituída por trabalhadores dessas empresas, o que significa que à anos atrás era basicamente um bairro de classe média. 0 comércio local é bastante desenvolvido, com a presença de supermercados, lojas de diferentes segmentos e pequenas, médias e grandes empresas.

0 índice de violência no bairro é alto, incluindo nesse cálculo o tráfico de drogas. Aliás, os assaltos estão frequentemente ligados ao tráfico, e infelizmente temos alguns de nossos alunos e ex-alunos envolvidos 
nesses índices.

O bairro é servido por três linhas de ônibus, sendo que duas destas linhas só circulam de hora em hora. As entradas e saídas do bairro são restritas e se ligam à Rodovia Anchieta, dificultando a movimentação das pessoas.

\section{Identificação do problema e da oportunidade}

A identificação do problema partiu de um diagnóstico da Unidade Escolar. Para isso, foram observadas as principais avaliações externas, avaliações da equipe pedagógica, bem como relatórios internos de desempenho.

IDEB

Resultado IDEB para $8^{\mathrm{a}}$ série $/ 9^{\circ}$ ano

\begin{tabular}{|l|l|l|l|l|l|l|l|l|l|}
\hline ANO & $\mathbf{2 0 0 5}$ & $\mathbf{2 0 0 7}$ & $\mathbf{2 0 0 9}$ & $\mathbf{2 0 1 1}$ & $\mathbf{2 0 1 3}$ & $\mathbf{2 0 1 5}$ & $\mathbf{2 0 1 7}$ & $\mathbf{2 0 1 9}$ & $\mathbf{2 0 2 1}$ \\
\hline Metas projetadas & - & 3,8 & 4,0 & 4,2 & 4,6 & 5,0 & 5,3 & 5,5 & 5,8 \\
\hline Ideb observado & 3,8 & 4,0 & 4,3 & 4,3 & 4,4 & - & - & - & - \\
\hline
\end{tabular}

Fonte: INEP

Resultado IDEB para $3^{\text {a }}$ série Ensino Médio

\begin{tabular}{|l|l|l|l|l|l|l|l|l|l|}
\hline ANO & $\mathbf{2 0 0 5}$ & $\mathbf{2 0 0 7}$ & $\mathbf{2 0 0 9}$ & $\mathbf{2 0 1 1}$ & $\mathbf{2 0 1 3}$ & $\mathbf{2 0 1 5}$ & $\mathbf{2 0 1 7}$ & $\mathbf{2 0 1 9}$ & $\mathbf{2 0 2 1}$ \\
\hline Metas projetadas & - & 3,3 & 3,4 & 3,6 & 3,9 & 4,2 & 4,6 & 4,9 & 5,1 \\
\hline Ideb observado & 3,3 & 3,4 & 3,6 & 3,9 & 3,7 & - & - & - & - \\
\hline
\end{tabular}

Fonte: INEP

Avaliação estadual: SARESP

\begin{tabular}{|c|c|c|c|c|c|c|}
\hline \multirow[b]{2}{*}{$\begin{array}{l}\text { NÍVEIS DE } \\
\text { PROFICIENCIA }\end{array}$} & \multicolumn{2}{|c|}{ LÍNGUA PORTUGUESA } & \multicolumn{2}{|c|}{ MATEMÁTICA } & \multicolumn{2}{|c|}{ CIÊNCIAS DA NATUREZA } \\
\hline & $9^{\circ} \mathrm{ANO}$ EF & $3^{\circ} \mathrm{ANO}$ EM & $9^{\circ} \mathrm{ANO} \mathrm{EF}$ & $3^{\circ}$ ANO EM & $9^{\circ} \mathrm{ANO}$ EF & $3^{\circ} \mathrm{ANO}$ EM \\
\hline Abaixo do Básico & 19,6 & 22,9 & 30,4 & 31,4 & 19,6 & 25,8 \\
\hline Básico & 51,0 & 22,9 & 51,0 & 57,1 & 52,0 & 48,4 \\
\hline Adequado & 23,5 & 45,7 & 16,7 & 11,4 & 16,7 & 25,8 \\
\hline Avançado & 5,9 & 8,6 & 2,0 & 0,0 & 11,8 & 0,0 \\
\hline
\end{tabular}




\section{Avaliações e relatórios internos}

\begin{tabular}{|c|c|c|c|c|c|c|c|}
\hline Série/Ano & $\begin{array}{l}\text { Matrículas } \\
\text { iniciais }\end{array}$ & Evasão & Transf. & $\begin{array}{l}\text { Matrículas } \\
\text { finais }\end{array}$ & Disciplinas & Aprov. & Reprov. \\
\hline \multirow{8}{*}{$6^{\circ}$ ano } & \multirow{8}{*}{88} & \multirow{8}{*}{0} & \multirow{8}{*}{20} & \multirow{8}{*}{68} & Português & 67 & 1 \\
\hline & & & & & Matemática & 67 & 1 \\
\hline & & & & & História & 67 & 1 \\
\hline & & & & & Geografia & 67 & 1 \\
\hline & & & & & Ciências & 67 & 1 \\
\hline & & & & & $\begin{array}{l}\text { L. } \\
\text { Estrangeira }\end{array}$ & 67 & 1 \\
\hline & & & & & Ed. Física & 67 & 1 \\
\hline & & & & & Artes & 67 & 1 \\
\hline \multirow{8}{*}{$\begin{array}{l}7^{0} \text { ano/ } 6^{\mathrm{a}} \\
\text { série }\end{array}$} & \multirow{8}{*}{124} & \multirow{8}{*}{0} & \multirow{8}{*}{14} & \multirow{8}{*}{110} & Português & 107 & 3 \\
\hline & & & & & Matemática & 107 & 3 \\
\hline & & & & & História & 107 & 3 \\
\hline & & & & & Geografia & 107 & 3 \\
\hline & & & & & Ciências & 107 & 3 \\
\hline & & & & & $\begin{array}{l}\text { L. } \\
\text { Estrangeira }\end{array}$ & 107 & 3 \\
\hline & & & & & Ed. Física & 107 & 3 \\
\hline & & & & & Artes & 107 & 3 \\
\hline
\end{tabular}

\begin{tabular}{|c|c|c|c|c|c|c|c|}
\hline Série/Ano & $\begin{array}{l}\text { Matrículas } \\
\text { iniciais }\end{array}$ & Evasão & Transf. & $\begin{array}{l}\text { Matrículas } \\
\text { finais }\end{array}$ & Disciplinas & Aprov. & Reprov. \\
\hline \multirow{8}{*}{$\begin{array}{l}8^{0} \text { ano/ } 7^{a} \\
\text { série }\end{array}$} & \multirow{8}{*}{117} & \multirow{8}{*}{0} & \multirow{8}{*}{07} & \multirow{8}{*}{110} & Português & 107 & 3 \\
\hline & & & & & Matemática & 107 & 3 \\
\hline & & & & & História & 107 & 3 \\
\hline & & & & & Geografia & 107 & 3 \\
\hline & & & & & Ciências & 107 & 3 \\
\hline & & & & & $\begin{array}{l}\text { L. } \\
\text { Estrangeira }\end{array}$ & 107 & 3 \\
\hline & & & & & Ed. Física & 107 & 3 \\
\hline & & & & & Artes & 107 & 3 \\
\hline
\end{tabular}




\begin{tabular}{|c|c|c|c|c|c|c|c|}
\hline \multirow{8}{*}{$\begin{array}{l}9^{0} \text { ano/ } 8^{a} \\
\text { série }\end{array}$} & \multirow{8}{*}{124} & \multirow{8}{*}{02} & \multirow{8}{*}{13} & \multirow{8}{*}{109} & Português & 97 & 12 \\
\hline & & & & & Matemática & 92 & 17 \\
\hline & & & & & História & 98 & 0 \\
\hline & & & & & Geografia & 98 & 0 \\
\hline & & & & & Ciências & 93 & 16 \\
\hline & & & & & $\begin{array}{l}\text { L. } \\
\text { Estrangeira }\end{array}$ & 98 & 0 \\
\hline & & & & & Ed. Física & 98 & 0 \\
\hline & & & & & Artes & 98 & 0 \\
\hline
\end{tabular}

\begin{tabular}{|c|c|c|c|c|c|c|c|}
\hline Série/Ano & $\begin{array}{l}\text { Matrículas } \\
\text { iniciais }\end{array}$ & Evasão & Transf. & $\begin{array}{l}\text { Matrículas } \\
\text { finais }\end{array}$ & Disciplinas & Aprov. & Reprov. \\
\hline \multirow{12}{*}{$1^{\circ}$ ano E.M. } & \multirow{12}{*}{131} & \multirow{12}{*}{10} & \multirow{12}{*}{24} & \multirow{12}{*}{97} & Português & 57 & 2 \\
\hline & & & & & Matemática & 44 & 53 \\
\hline & & & & & História & 56 & 41 \\
\hline & & & & & Geografia & 57 & 40 \\
\hline & & & & & Biologia & 59 & 38 \\
\hline & & & & & $\begin{array}{l}\text { L. } \\
\text { Estrangeira }\end{array}$ & 59 & 38 \\
\hline & & & & & Ed. Física & 59 & 38 \\
\hline & & & & & Artes & 59 & 38 \\
\hline & & & & & Química & 48 & 49 \\
\hline & & & & & Física & 59 & 38 \\
\hline & & & & & Filosofia & 59 & 38 \\
\hline & & & & & Sociologia & 59 & 38 \\
\hline
\end{tabular}

\begin{tabular}{|c|c|c|c|c|c|c|c|}
\hline Série/Ano & $\begin{array}{l}\text { Matrículas } \\
\text { iniciais }\end{array}$ & Evasão & Transf. & $\begin{array}{l}\text { Matrículas } \\
\text { finais }\end{array}$ & Disciplinas & Aprov. & Reprov. \\
\hline \multirow{6}{*}{$2^{\circ}$ ano E.M. } & \multirow{6}{*}{100} & \multirow{6}{*}{01} & \multirow{6}{*}{21} & \multirow{6}{*}{78} & Português & 60 & 18 \\
\hline & & & & & Matemática & 51 & 27 \\
\hline & & & & & História & 62 & 16 \\
\hline & & & & & Geografia & 61 & 17 \\
\hline & & & & & Biologia & 62 & 16 \\
\hline & & & & & $\begin{array}{l}\text { L. } \\
\text { Estrangeira }\end{array}$ & 62 & 16 \\
\hline
\end{tabular}




\begin{tabular}{|c|c|c|c|c|c|c|c|}
\hline & & & & & Ed. Física & 62 & $\overline{16}$ \\
\hline & & & & & Artes & 62 & 16 \\
\hline & & & & & Química & 62 & $\overline{16}$ \\
\hline & & & & & Física & 60 & 18 \\
\hline & & & & & Filosofia & $\overline{61}$ & $\overline{17}$ \\
\hline & & & & & Sociologia & 61 & 17 \\
\hline \multirow{12}{*}{$3^{\circ}$ ano E.M. } & \multirow{12}{*}{62} & \multirow{12}{*}{03} & \multirow{12}{*}{19} & \multirow{12}{*}{43} & Português & 42 & 1 \\
\hline & & & & & Matemática & 41 & 2 \\
\hline & & & & & História & 42 & 1 \\
\hline & & & & & Geografia & 42 & 1 \\
\hline & & & & & Biologia & 42 & $\overline{1}$ \\
\hline & & & & & $\begin{array}{l}\text { L. } \\
\text { Estrangeira }\end{array}$ & 42 & 1 \\
\hline & & & & & Ed. Física & $\overline{42}$ & $\overline{1}$ \\
\hline & & & & & Artes & 42 & 1 \\
\hline & & & & & Química & 41 & 2 \\
\hline & & & & & Física & 42 & 1 \\
\hline & & & & & Filosofia & 42 & 1 \\
\hline & & & & & Sociologia & 42 & 1 \\
\hline
\end{tabular}

Principais problemas identificados

1. Baixo rendimento dos alunos das 03 séries do Ensino Médio, atrelado à baixa expectativa de mudança de vida proporcionada pela educação. Observando as tabelas anteriores é possível perceber que os resultados obtidos pelos alunos do Ensino Fundamental são superiores aos do Ensino Médio, tanto nas avaliações internas como nas avaliações externas. Além disso, o número de alunos matriculados cai consideravelmente, o que indica que estes alunos foram para o mercado de trabalho e, com isso, muitas vezes desistem da escola.

2. Despreparo de uma parte do corpo docente para lidar com os problemas de aprendizagem apresentados pelos alunos ao longo do Ensino Médio. Aulas sem sentido, desmotivadoras, que não tem significância para a vida, para o dia-a-dia do aluno aumentam as probabilidades dos alunos apresentarem dificuldades no processo ensino-aprendizagem. Tudo aliado às questões da adolescência, em que os alunos questionam a todo tempo a autoridade do professor em sala de aula e sua competência para o oficio de ensinar, acabam por promover problemas disciplinares, em especial no $1^{\circ}$ ano do Ensino Médio.

3. Falta de conhecimento por parte do corpo docente para trabalhar com competências e habilidades nos diferentes níveis de proficiência. Nos últimos anos temos visto a educação se pautar pelo conhecimento de competências e habilidades. Infelizmente, só ter o conhecimento teórico não é suficiente para garantir que esses conceitos sejam aplicados pelos professores em sala de aula. Quando associamos estes conceitos a aqueles que definem os níveis de proficiência nas 
avaliações externas é que podemos enxergar o quanto os professores estão despreparados para entender e aplicar esta forma de trabalhar os conteúdos e o processo de ensino aprendizagem.

4. Desinteresse por parte do corpo docente e discente. A definição mais triste e mais verdadeira para explicar essa situação é a máxima que diz: "O aluno finge que aprende, o professor finge que ensina e fica tudo bem". Como promover o interesse nos alunos que não conseguem entender o que estão fazendo na escola? Como desenvolver neles a competência leitora e escritora, se eles não conseguem enxergar significado para isso? A desmotivação está diretamente relacionada à falta de conhecimento e uma situação gera a outra, ou seja, como ministrar aulas para alunos que não querem ter aula, pois não entendem qual a finalidade desta?

A vista de tudo isso, considerando as realidades da escola, o trabalho pedagógico a ser desenvolvido deve ter foco no desenvolvimento da competência leitora e escritora, dando significado ao que os alunos estão aprendendo, relacionando o aprendizado com seu cotidiano.

\begin{tabular}{|l|l|l|l|l|l|}
\hline Problemas & G & U & T & GxUxT & Prioridade \\
\hline Problema 1 & 5 & 5 & 4 & 100 & $2^{0}$ \\
\hline Problema 2 & 5 & 4 & 4 & 80 & $3^{\circ}$ \\
\hline Problema 3 & 4 & 4 & 4 & 64 & $4^{0}$ \\
\hline Problema 4 & 5 & 5 & 5 & 125 & $1^{\circ}$ \\
\hline
\end{tabular}

\section{Detalhamento do problema}

Utilizou-se o Diagrama de Causa e Efeito para detalhar o problema:

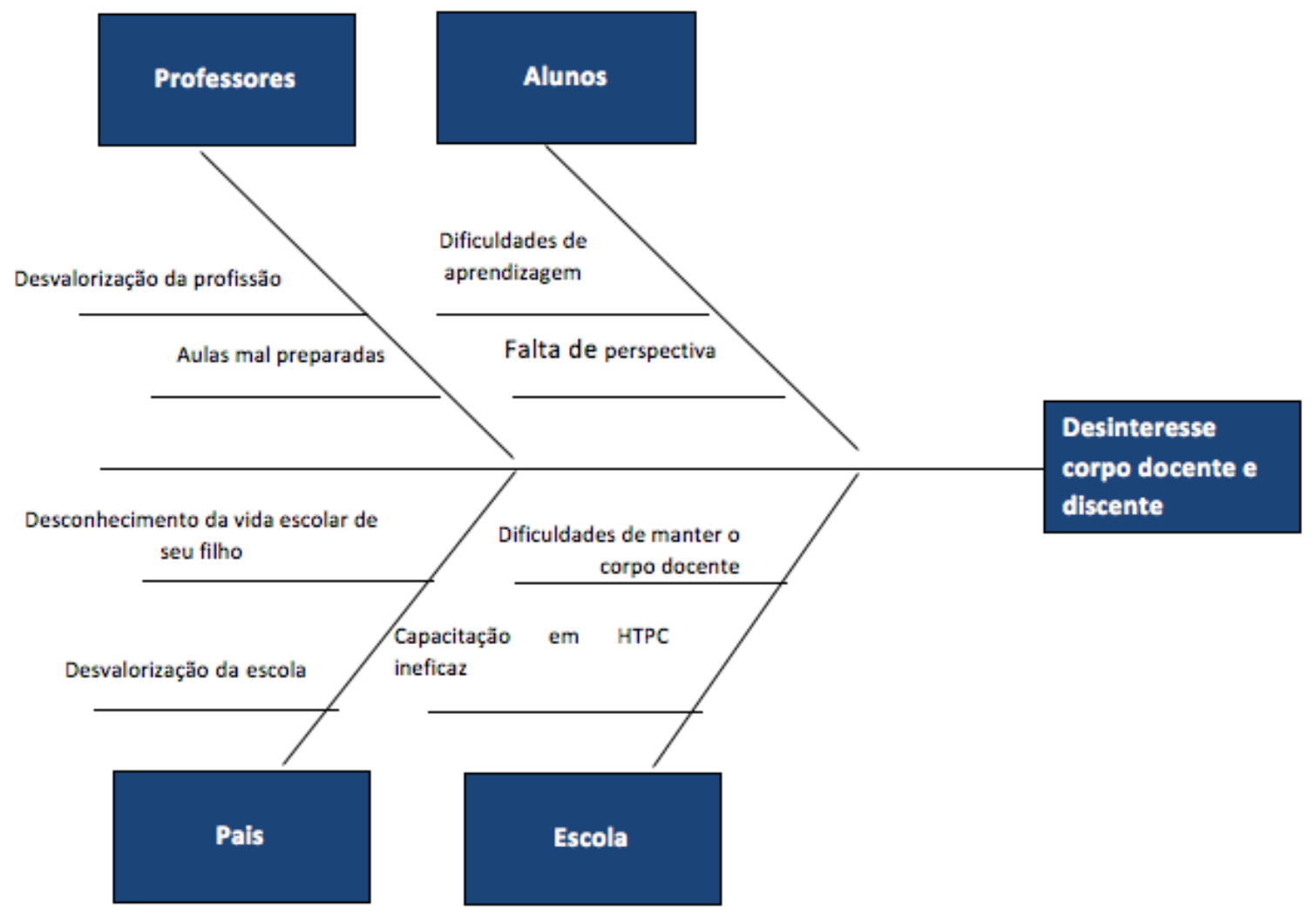




\section{Análise SWOT}

A partir das pesquisas realizadas pela equipe escolar e das discussões sobre o contexto da escola, foi desenvolvida a seguinte Matriz SWOT:

\begin{tabular}{|c|c|c|}
\hline & Aspectos favoráveis & Aspectos desfavoráveis \\
\hline \multirow[b]{2}{*}{ 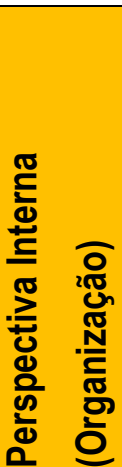 } & FORÇAS & FRAQUEZAS \\
\hline & $\begin{array}{l}\text { Grande grupo de professores efetivo; } \\
\text { Equipe gestora coesa; } \\
\text { Professores dispostos a implementar } \\
\text { mudanças }\end{array}$ & $\begin{array}{l}\text { Alto índice de faltas de alunos e } \\
\text { professores } \\
\text { Problemas disciplinares motivados por } \\
\text { problemas pedagógicos } \\
\text { Desinteresse dos pais em participar da } \\
\text { vida escolar de seus filhos }\end{array}$ \\
\hline \multirow[b]{2}{*}{ 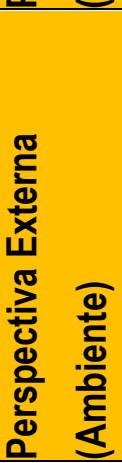 } & OPORTUNIDADES & AMEAÇAS \\
\hline & $\begin{array}{l}\text { Parceria com empresa vizinha } \\
\text { Parceria com centro cultural do bairro } \\
\text { Parceria com UBS }\end{array}$ & $\begin{array}{l}\text { Segurança Pública falha no bairro } \\
\text { Atuação do tráfico de drogas nas } \\
\text { comunidades } \\
\text { Problemas com obras de saneamento } \\
\text { público e contra enchentes }\end{array}$ \\
\hline
\end{tabular}

Tendo em vista o exposto na matriz acima, acredito que a escola tenha mais Forças do que Fraquezas, pois 0 fato de contarmos com grande número de Professores Efetivos, que estão na escola já a alguns anos, permite a implementação de Projeto a Médio prazo, sem haja grandes alterações no grupo participante, facilitando a operacionalização do mesmo ao longo do período de aplicação. Oportunidades também se sobressaem às Ameaças, pois, apesar dos problemas serem muito sérios, dentro da escola eles se manifestam de forma discreta e o desenvolvimento do Projeto pode se tornar um grande marco para a minimização das mesmas, principalmente no que se refere aos problemas com o tráfico de drogas.

\section{Ações corretivas}

Visando preparar a organização para o desenvolvimento do projeto, no intuito de combater as fraquezas e reduzir os possíveis impactos das ameaças, foram definidas as seguintes ações:

1. Convocar pais e/ou responsáveis pelos alunos faltosos para conversas com a equipe gestora, informando quais são os trâmites legais nestes casos;

2. Auxiliar os professores na elaboração de aulas mais significativas;

3. Promover debates, junto com o Grêmio Estudantil, para minimizar os problemas disciplinares, diretamente relacionados aos problemas de aprendizagem;

4. Disponibilização de materiais e espaços para favorecer o desenrolar da aula;

5. Oportunizar a retirada de títulos na biblioteca pelos alunos e comunidade escolar em geral, estimulando a leitura;

6. Promover maior utilização da sala de leitura, apresentando-a como um espaço agradável e adequado ao desenvolvimento pessoal dos alunos 


\section{Oportunidade identificada}

A ideia central do Projeto é a de implantar a Oficina Teatral, através da qual os alunos poderão desenvolver as relações interpessoais, conhecer diferentes obras literárias e interpretá-las, despertar para a criticidade, aprender a realizar pesquisas, se enxergar como elemento participante de um grupo, comunidade e por fim, da sociedade.

O fato do aluno estabelecer contato com o outro permite que ele conheça realidades diferentes, outras dimensões de uma mesma situação e aprenda a conviver com as diferenças, despertando para uma sociedade da qual faz parte e, portanto, tem direitos e deveres. Entre estes direitos, está o de ter educação de qualidade, que 0 atenda de maneira total e garanta a ele a opção de escolher o melhor caminho para sua vida. Isso tudo só é possível se ele tiver condições de avaliar suas possibilidades, tiver conhecimento da realidade em que vive e quais são as metas que pretende atingir e, para isso, precisa adquirir conhecimentos que estão relacionados à sua vida escolar.

Os problemas sociais não serão erradicados, mas pretendemos com esse Projeto apresentar uma alternativa para nossos alunos e dessa forma, esperamos ter uma redução não taxa de evasão e de retenção, melhorias nos problemas disciplinares e nas relações entre professores e alunos.

\section{Detalhamento do produto/serviço e/ou processo}

\section{Foco do projeto}

O objetivo desse projeto é despertar nos alunos uma relação com a escola por meio de trabalhos coletivos, relações interpessoais e do desenvolvimento de um olhar mais crítico. Através do Jogo Teatral espera-se que 0 aluno possa perceber a capacidade criativa implícita no ser humano, conhecer diferentes fontes de pesquisa, ter contato com diferentes formas de expressão artísticas e culturais e perceber a necessidade do outro no desenvolvimento em qualquer área. Assim, durante os Jogos Teatrais o aluno vivencia a situação de participante e de público, estabelecendo uma relação no grupo que o leve a perceber que faz parte de uma comunidade e, por conseguinte, de uma sociedade.

O coordenador do jogo se apresenta como mediador, inferindo questões a partir dos pontos de vista apresentados no grupo, norteando os caminhos através de pesquisas coletivas. O resultado que se espera é que dessa forma, os jovens possam iniciar a compreensão de sua importância na sociedade.

Série ou conjunto de séries beneficiadas: Ensino Fundamental Il e Ensino Médio

Disciplina ou conjunto de disciplinas trabalhadas: Língua Portuguesa, Artes, Educação Física, História, Geografia.

\section{Etapas do projeto}

O projeto será composto pelas seguintes etapas:

\section{Etapa 1 - JOGOS TEATRAIS}

Objetivo: Promover o início de trabalhos coletivos, de maneira que o aluno perceba que faz parte de um grupo e que as regras de convivência precisam ser seguidas para que todos atinjam a meta estabelecida.

Impacto na aprendizagem: Organização de estudos, melhora na argumentação e na escrita.

Atividades a serem realizadas: Procedimentos lúdicos com regras explícitas com os próprios alunos atuando como atores e plateia. Nos jogos teatrais o grupo de pessoas que joga pode se dividir em "times" que se alternam nas funções de "atores" e "público", ou seja, as pessoas "jogam" para outros que as "observam" e "observam" outros que "jogam".

\section{Atividade 1.1}

Descrição: Trazer a tona questões vivenciadas pelos alunos em relação à coletividade e a sociedade.

Duração: 04 meses 
Recursos necessários: CD player, materiais de papelaria diversos, cópias de textos e imagens

Equipe envolvida: 02 Arte-Educadores e 02 Educadores Assistentes

\section{Atividade 1.2}

Descrição: Criação baseada nos temas trazidos pelos alunos durante o desenvolvimento dos jogos

Duração: 04 meses

Recursos necessários: CD player, materiais de papelaria e adereços para execução das aulas, cortina, cópias de textos e imagens

Equipe envolvida: 02 Arte-Educadores e 02 Educadores Assistentes

\section{Etapa 2 - OFICINAS DE INICIAÇÃO TEATRAL}

Objetivo: Possibilidade de despertar a criticidade.

Impacto na aprendizagem: Compreensão das relações dos diferentes personagens sociais e sua posição como elo dessa sociedade.

Atividades a serem realizadas: Incitar a criação e entrar em contato com diferentes expressões artísticas para iniciar a criação de um repertório cultural nos alunos.

\section{Atividade 2.1}

Descrição: Criação de texto baseado nas intersecções entre textos apresentados e problemas vivenciados pelos alunos.

Duração: 04 meses

Recursos necessários: CD player, materiais de papelaria e adereços para execução das aulas, cortina, cópias de textos e imagens

Equipe envolvida: 02 Arte-Educadores e 02 Educadores Assistentes

\section{Atividade 2.2}

Descrição: Apreciação Artística

Duração: 01 por mês, a partir do $6^{\circ}$ mês do projeto perfazendo um total de 12 visitas

Recursos necessários: transporte, ingressos, cachês para grupos que se apresentem na escola.

Equipe envolvida: 02 Arte-Educadores, 02 Educadores Assistentes, Professores e Equipe Gestora.

\section{Atividade 2.3}

Descrição: Desenvolvimento de cenários e adereços

Duração: 04 meses

Recursos necessários: tecidos diversos, materiais de armarinhos em geral

Equipe envolvida: 02 Arte-Educadores, 02 Educadores Assistentes, Professores e Equipe Gestora.

\section{Etapa 3 - Produção de Espetáculo}

Objetivo: Desenvolvimento cultural e crescimento pessoal dos alunos

Impacto na aprendizagem: Leitura crítica de fenômenos, abandonando as explicações baseadas na relação "causa-efeito"; colocar-se como sujeito ativo de seu próprio desenvolvimento.

Atividades a serem realizadas: Leitura crítica de peças literárias, jornais e revistas. Pesquisas em diferentes fontes para elaboração de texto teatral. Desenvolvimento de adereços e cenários para enriquecimento do espetáculo 


\section{Atividade 3.1}

Descrição: Desenvolvimento do texto do espetáculo

Duração: 09 meses

Recursos necessários: livros, revistas, jornais, computador

Equipe envolvida: 02 Arte-Educadores, 02 Educadores Assistentes, Professores de Língua Portuguesa

\section{Atividade 3.2}

Descrição: Desenvolvimento de cenários, adereços e maquiagem

Duração: 06 meses

Recursos necessários: tecidos diversos, materiais de armarinhos em geral, maquiagem e pinturas para pele

Equipe envolvida: 02 Arte-Educadores, 02 Educadores Assistentes, Maquiador

\section{Atividade 3.3}

Descrição: Desenvolvimento de trilha sonora para o espetáculo

Duração: 06 meses

Recursos necessários: CD player, mp3, computador, CD-RW e pen drive

Equipe envolvida: 02 Arte-Educadores, 02 Educadores Assistentes

\section{Casos de sucesso}

Nome do Projeto: POSSIBILIDADES DE APRENDIZAGEM COLABORATIVA NA OFICINA DE JOGOS TEATRAIS

Nome da organização: EMEF Santa Terezinha

Local: Pelotas / RS

Período em que foi realizado: 1998 à 2009

Breve relato do contexto anterior ao projeto: Alunos desinteressados, pais que não sabiam como lidar com as novas situações cotidianas e professores desestimulados diante das transformações ocorridas na escola e na sociedade.

Principais atividades desenvolvidas: 0 Jogo Teatral apresenta 3 fases: a primeira em que 0 orientador da as instruções do jogo; na segunda os jogadores tem um problema de natureza cênica, ou seja, o foco; e na terceira é realizada a avaliação do processo por todos, incluindo a plateia.

Resumo dos principais resultados alcançados: Contribuição na aprendizagem de colaboração, troca de ideias entre os pares, praticar a solidariedade, respeito e a inclusão na interação social, possibilitando a aprendizagem de valores sociais importantes na sociedade atual

Fonte:

http://www.portalanpedsul.com.br/admin/uploads/2010/Educacao_e_Arte/Trabalho/08_42_42_POSSIBILIDAD ES_DA_APRENDIZAGEM_COLABORATIVA_NA_OFICINA_DE_JOGOS_TEATRAIS.PDF - acesso em $11 / 10 / 2015$

\section{Novidade trazida pelo projeto}

0 projeto tem por finalidade promover maior envolvimento dos alunos com a escola, despertando nos mesmos, através da Arte, o sentimento de pertencimento a esta escola, reduzindo o desinteresse e apatia que promovem a evasão escolar e o baixo rendimento. Trata-se de uma oferta de serviço que não existe até o presente momento na comunidade escolar e que representa um canal de acesso à cultura.

A apropriação dessa cultura por parte dos alunos proporcionaria aos mesmos condições de participar mais 
ativamente da comunidade em que estão inseridos, apresentando ações de cidadania e a proposição de ações inovadoras para resolver problemas comuns da comunidade em que estão inseridos.

\section{Cronograma de execução}

\begin{tabular}{|c|c|c|c|c|c|c|c|c|c|c|c|c|c|}
\hline \multirow{2}{*}{\multicolumn{2}{|c|}{ Atividades }} & \multicolumn{4}{|c|}{ Ano 1} & \multicolumn{4}{|c|}{ Ano 2} & \multicolumn{4}{|c|}{ Ano 3} \\
\hline & & \multirow{2}{*}{$\begin{array}{l}\text { Jan- } \\
\text { Mar }\end{array}$} & \multirow{2}{*}{$\begin{array}{l}\text { Abr- } \\
\text { Jun }\end{array}$} & \multirow{2}{*}{$\begin{array}{l}\text { Jul- } \\
\text { Set }\end{array}$} & \multirow{2}{*}{$\begin{array}{l}\text { Out- } \\
\text { Dez }\end{array}$} & \multirow{2}{*}{$\begin{array}{l}\text { Jan- } \\
\text { Mar }\end{array}$} & \multirow{2}{*}{$\begin{array}{l}\text { Abr- } \\
\text { Jun }\end{array}$} & \multirow{2}{*}{$\begin{array}{l}\text { Jul- } \\
\text { Set }\end{array}$} & \multirow{2}{*}{\begin{tabular}{|l} 
Out- \\
Dez
\end{tabular}} & \multirow{2}{*}{$\begin{array}{l}\text { Jan- } \\
\text { Mar }\end{array}$} & \multirow{2}{*}{$\begin{array}{l}\text { Abr- } \\
\text { Jun }\end{array}$} & \multirow{2}{*}{$\begin{array}{l}\text { Jul- } \\
\text { Set }\end{array}$} & \multirow{2}{*}{$\begin{array}{l}\text { Out- } \\
\text { Dez }\end{array}$} \\
\hline \multirow{2}{*}{ Etapa 1} & Ativ. 1.1 & & & & & & & & & & & & \\
\hline & \begin{tabular}{|l|} 
Ativ. 1.2 \\
\end{tabular} & & & & & & & & & & & & \\
\hline \multirow{3}{*}{ Etapa 2} & Ativ. 2.1 & & & & & & & & & & & & \\
\hline & Ativ. 2.2 & & & & & & & & & & & & \\
\hline & Ativ. 2.3 & & & & & & & & & & & & \\
\hline \multirow{3}{*}{ Etapa 3} & Ativ. 3.1 & & & & & & & & & & & & \\
\hline & Ativ. 3.2 & & & & & & & & & & & & \\
\hline & Ativ. 3.3 & & & & & & & & & & & & \\
\hline
\end{tabular}

\section{Gestão Estratégica}

\section{Objetivos estratégicos}

\begin{tabular}{|c|c|c|c|}
\hline Objetivos & Metas & Indicadores & Acompanhamento \\
\hline \multirow{3}{*}{$\begin{array}{l}\text { Desenvolver a } \\
\text { competência } \\
\text { leitora nos alunos }\end{array}$} & $\begin{array}{l}\text { Alcançar a meta estabelecida } \\
\text { pelo corpo docente e equipe } \\
\text { gestora para as avaliações } \\
\text { bimestrais. }\end{array}$ & $\begin{array}{l}\text { Resultados obtidos } \\
\text { pelos alunos nas } \\
\text { avaliações }\end{array}$ & $\begin{array}{l}\text { Análise bimestral, pelo Conselho } \\
\text { de Classe, com verificação das } \\
\text { habilidades que ainda não foram } \\
\text { alcançadas. }\end{array}$ \\
\hline & $\begin{array}{l}\text { Alcançar a meta estabelecida } \\
\text { pela SEE-SP para o SARESP } \\
\text { em Língua Portuguesa até o } \\
\text { final do projeto }\end{array}$ & $\begin{array}{l}\text { Resultado para a } \\
\text { avaliação do } \\
\text { SARESP } 2018\end{array}$ & $\begin{array}{l}\text { Análise bimestral e anual pelo } \\
\text { Conselho de Classe, com } \\
\text { verificação das habilidades a } \\
\text { serem desenvolvidas ao longo do } \\
\text { projeto para obtenção do índice. }\end{array}$ \\
\hline & $\begin{array}{l}\text { Aumento do empréstimo de } \\
\text { livros pela biblioteca em } 10 \% \\
\text { no primeiro ano, } 15 \% \text { no } \\
\text { segundo ano e } 25 \% \text { no } \\
\text { terceiro ano }\end{array}$ & $\begin{array}{ll}\text { Fichas } & \text { de } \\
\text { empréstimo } & \text { de } \\
\text { livros } & \end{array}$ & $\begin{array}{l}\text { Verificações numéricas com } 0 \\
\text { voluntário da biblioteca }\end{array}$ \\
\hline \multirow{2}{*}{$\begin{array}{l}\text { Desenvolver a } \\
\text { competência } \\
\text { escritora nos } \\
\text { alunos }\end{array}$} & $\begin{array}{l}\text { Alcançar a meta estabelecida } \\
\text { pelo corpo docente e equipe } \\
\text { gestora para as avaliações } \\
\text { bimestrais }\end{array}$ & $\begin{array}{l}\text { Resultados obtidos } \\
\text { pelos alunos nas } \\
\text { avaliações } \\
\text { internas }\end{array}$ & $\begin{array}{l}\text { Análise bimestral, pelo Conselho } \\
\text { de Classe, com verificação das } \\
\text { habilidades que ainda não foram } \\
\text { alcançadas }\end{array}$ \\
\hline & $\begin{array}{l}\text { Alcançar a meta estabelecida } \\
\text { pela SEE-SP para SARESP }\end{array}$ & $\begin{array}{lr}\text { Resultado } & \text { para } \\
\text { avaliação } & \text { do }\end{array}$ & $\begin{array}{l}\text { Análise bimestral e anual pelo } \\
\text { Conselho de Classe, com }\end{array}$ \\
\hline
\end{tabular}




\begin{tabular}{|c|c|c|c|}
\hline & $\begin{array}{l}\text { em Língua Portuguesa até o } \\
\text { final do Projeto }\end{array}$ & SARESP 2018 & $\begin{array}{l}\text { verificação das habilidade a } \\
\text { serem desenvolvidas ao longo do } \\
\text { projeto para obtenção do índice }\end{array}$ \\
\hline & $\begin{array}{l}\text { Aumentar a utilização da sala } \\
\text { de leitura pelos alunos do } \\
\text { Ensino Médio em } 10 \% \text { ao } \\
\text { longo dos anos do projeto }\end{array}$ & $\begin{array}{l}\text { Número que vezes } \\
\text { que a sala foi } \\
\text { requisitada na } \\
\text { semana }\end{array}$ & $\begin{array}{l}\text { Verificação das planilhas para } \\
\text { quantificar a frequência semanal }\end{array}$ \\
\hline \multirow{2}{*}{$\begin{array}{l}\text { Diminuir o índice } \\
\text { de evasão escolar }\end{array}$} & $\begin{array}{l}\text { Diminuir em } 20 \% \text { a retenção } \\
\text { por faltas no primeiro ano; } \\
30 \% \text { no segundo ano e } 40 \% \\
\text { no terceiro ano }\end{array}$ & $\begin{array}{l}\text { Índice de faltas } \\
\text { mensais } \\
\begin{array}{l}\text { apontados nos } \\
\text { diários }\end{array}\end{array}$ & $\begin{array}{l}\text { Controle mensal das faltas das } \\
\text { turmas e convocação dos pais } \\
\text { dos alunos que apresentarem } \\
\text { número elevado de faltas }\end{array}$ \\
\hline & $\begin{array}{l}\text { Aumentar o fluxo em } 5 \% \\
\text { no primeiro ano, } 15 \% \text { no } \\
\text { segundo ano e } 30 \% \text { no } \\
\text { terceiro ano para atingir o } \\
\text { índice do IDESP }\end{array}$ & $\begin{array}{lr}\text { Taxas } & \text { de } \\
\text { abandono } & \mathrm{e} \\
\text { transferência } & \text { no } \\
\text { sistema } & \end{array}$ & $\begin{array}{l}\text { Controle bimestral das faltas e } \\
\text { encaminhamento ao Conselho } \\
\text { Tutelar em casos de abandono }\end{array}$ \\
\hline
\end{tabular}

\section{Continuidade do projeto}

Após o término do financiamento pelo edital, o Projeto terá continuidade apoiado nos materiais adquiridos para tal finalidade, e que continuarão de posse da escola. Além disso, como informado na Matriz Swot, contamos com um grande número de professores efetivos que, ao longo dos anos de financiamento, serão orientados e capacitados para o desenvolvimento adequado e significativo do projeto e, sendo assim poderão continuar atuando dentro dos moldes que foram adotados durante o período projetado. Alem disso, a escola oferecerá em horários de ATPCs oficinas e aprimoramento aos professores, tornando esse momento um real momento de crescimento profissional e de valorização do trabalho docente.

\section{Marketing e Comunicação}

\section{Lançamento do projeto}

Inicialmente, pretendemos gerar um sentimento de "curiosidade" na comunidade escolar acerca do projeto que será lançado, utilizando para isso redes sociais e a divulgação de peças promocionais, tipo banners, dentro da escola. A intenção é gerar tamanha curiosidade que a comunidade passe a discutir sobre qual a novidade que será implantada e assim compareça ao evento de lançamento. $O$ evento será programado para ocorrer como uma Aula Aberta do "Jogos Teatrais", em que os presentes participarão como "atores" e também como "plateia", vivenciando minimamente o que se propõe como ação durante o desenrolar do projeto.

\section{Canais de comunicação e acompanhamento do projeto}

\section{Marketing interno}

Material em vídeo que será disponibilizado na página do Projeto nas Redes Sociais, atraindo e integrando professores, funcionários, pais e alunos à nova proposta. Utilização de cartazes informando a evolução do Projeto, informações essas que também serão disponibilizadas on-line e através de e-mail quando se tratar da divulgação entre a equipe gestora de processos internos para o desenrolar do projeto. Para comunicações rápidas, utilizaremos um meio com o qual já temos resultados positivos que é o WhatsApp. Os cartazes serão produzidos ao final de cada etapa concluída. Os e-mail serão utilizados para a divulgação das novas etapas e o WhatsApp a todo momento. 


\section{Marketing externo}

Serão produzidos cartazes para afixação na escola, e nos parceiros da escola no projeto. Além deste mecanismo de divulgação, também serão encaminhadas circulares aos pais dos alunos com informações relevantes acerca do andamento do projeto, etapas concluídas e próximas etapas. Divulgação semanal nas redes sociais das vivencias propostas nas aulas. A equipe gestora da escola se encarregará da elaboração das circulares. Os alunos do projeto serão responsáveis pela elaboração dos cartazes, juntamente com os oficineiros, bem como também ficarão responsáveis pelas informações que serão postadas nas redes sociais. Os custos para essas ações já estão previstos no plano de recursos do projeto.

\section{Parceiros estratégicos}

- ZF Sachs: empresa multinacional do ramo metalúrgico, instalada no entorno da escola. A empresa irá contribuir financeiramente com o Projeto, ficando responsável pela parcela necessária para garantir a Atividade 2.2 (Apreciação Artística) que ocorrerem fora da escola. Assim, fornecerão os ingressos e 0 transporte necessários para tal atividade.

- Centro Cultural M'boe: centro cultural instalado no entorno, que atende crianças carentes e idosos. A parceria prevê contribuições de ordem artística, tais como orientações para elaboração de maquiagem artística e aulas de corte e costura para elaboração de figurinos.

- Contrapartida da E.E.Prof. Antonio Nascimento: a escola oferecerá suas instalações para 0 desenvolvimento do projeto, equipe gestora que irá administrar as etapas do mesmo, alimentação para os alunos participantes, além de todas as condições para o desenvolvimento da oficina envolvendo gastos com água, energia elétrico, telefonia.

Os contatos com os parceiros serão realizados pela equipe gestora, através de visita para apresentar a proposta do projeto a ser desenvolvido. A apresentação do projeto irá se basear no objetivo principal que é o de aumentar a competência leitora e escritora dos alunos, para que a escola possa atingir as metas oficiais estabelecidas pela SEE-SP ou pelo Governo Federal. Esse desenvolvimento afetará diretamente a empresa que assim poderá buscar mão de obra melhor formada no próprio entorno e, com isso, obtendo maior aceitação pela comunidade. No caso do Centro Cultural, o estreitamento dos laços já estabelecidos será muito proveitoso, tendo em vista que muitas das crianças já são atendidas nos seus programas, mas lhes falta espaço para ampliar esse atendimento e a escola poderia ofertar tal espaço, além da divulgação na comunidade do trabalho desenvolvido por ele.

\section{Divulgação de resultados}

Como o projeto tem por objetivo aumentar a competência leitora e escritora dos alunos, os resultados parciais também são importantes. Assim, bimestralmente através do acompanhamento dos resultados obtidos pelos alunos, mensurados pelas notas que alcançaram nas diferentes disciplinas, servirá para monitorar o seu desenvolvimento e balizar as ações a serem propostas para as etapas seguintes. Ao final do ano, com a divulgação dos resultados finais dos alunos, os resultados com projeto serão apresentados à comunidade escolar através de relatórios, que serão divulgados na página do projeto e em reunião de pais. Além disso, ao final de cada ano do projeto acontecerá uma apresentação dos alunos integrantes, que irão mostrar para a comunidade o trabalho desenvolvido ao longo daquela etapa.

\section{Equipe do Projeto}

A E.E. Prof. Antonio Nascimento é uma instituição de ensino de médio porte, com aproximadamente 600 alunos matriculados, distribuídos em dois turnos de funcionamento. Sua organização hierárquica é composta por uma diretora e uma vice-diretora, uma professora coordenadora do ensino médio e uma professora coordenadora do ensino fundamental, seis agentes de organização escolar e 34 professores. Os funcionários de limpeza e merendeira são terceirizados. Esta gestão é marcada pela preocupação com a aprendizagem e com a qualidade da educação ofertada aos nossos alunos do ensino fundamental e médio. 


\section{Equipe interna}

\begin{tabular}{|c|c|c|c|c|}
\hline Cargo & Formação & $\begin{array}{l}\text { Tempo na } \\
\text { escola }\end{array}$ & Experiência anterior & $\begin{array}{l}\text { Responsável pelas } \\
\text { atividades: }\end{array}$ \\
\hline Diretora & Pós-Graduação & 10 anos & $\begin{array}{l}\text { Professora com } 25 \\
\text { anos de experiência } \\
\text { em Ensino Médio na } \\
\text { Rede Pública e Privada } \\
\text { e Orientação } \\
\text { Educacional }\end{array}$ & $\begin{array}{l}\text { Acompanhamento de } \\
\text { todas as etapas e } \\
\text { responsável direto } \\
\text { pelas atividades } 2.2 \text {, } \\
2.3 \text { e } 3.2\end{array}$ \\
\hline Vice-Diretora & Pós-Graduação & 8 anos & $\begin{array}{l}\text { Professora com } 20 \\
\text { anos de experiência na } \\
\text { Rede Pública e Privada }\end{array}$ & $\begin{array}{l}\text { Acompanhamento de } \\
\text { todas as etapas e } \\
\text { responsável pelas } \\
\text { atividades } 2.2,2.3 \text { e } \\
3.2\end{array}$ \\
\hline $\begin{array}{l}\text { Coordenadora } \\
\text { Pedagógica E.FII }\end{array}$ & Graduada & 20 anos & $\begin{array}{l}\text { Professora com } 25 \\
\text { anos de experiência na } \\
\text { Rede Publica e Privada }\end{array}$ & $1.1,2.1,2.3,3.1$ e 3.3 \\
\hline $\begin{array}{l}\text { Coordenador } \\
\text { Pedagógica E.M. }\end{array}$ & Graduada & 1 ano & $\begin{array}{l}\text { PCNP na Diretoria de } \\
\text { Ensino do município e } \\
15 \text { anos como } \\
\text { Professora da } \\
\text { Publica }\end{array}$ & $1.1,2.1,2.3,3.1$ e 3.2 \\
\hline $\begin{array}{l}\text { Professora } \\
\text { Português }\end{array}$ & Pós-Graduação & 5 anos & $\begin{array}{l}\text { Professora com } 10 \\
\text { anos de experiência na } \\
\text { Rede Pública e Privada }\end{array}$ & $\begin{array}{l}1.2,2.1,2.3,3.1,3.2, \\
3.3\end{array}$ \\
\hline
\end{tabular}

\section{Profissionais externos}

\begin{tabular}{|l|l|l|}
\hline Tipo de profissional & Competências necessárias & Participação no projeto \\
\hline Arte-educador & $\begin{array}{l}\text { Formação em Teatro e/ou Artes } \\
\text { Cênicas }\end{array}$ & $\begin{array}{l}\text { Regência das aulas dos jogos } \\
\text { teatrais }\end{array}$ \\
\hline Educador Assistente & $\begin{array}{l}\text { Estudante de Teatro ou Artes } \\
\text { Cênicas ou Comunicação }\end{array}$ & Assistência ao regente das aulas \\
\hline
\end{tabular}




\section{Karla Elisa Armellini}

\section{Plano Financeiro}

Plano Financeiro elaborado de acordo com o edital n 11 - "Projetos Inovadores em Educação", Fundação

Novo Brasil - Educação para o Futuro.

\section{Investimentos (despesas de capital)}

\begin{tabular}{|l|l|l|l|}
\hline Obras e infraestrutura & Ano 1 & Ano 2 & Ano 3 \\
\hline Pintura da sala & $1.500,00$ & $1.000,00$ & $1.000,00$ \\
\hline Trilho para cortina e acessórios & 250,00 & 100,00 & 100,00 \\
\hline Lâmpadas e reatores & 260,00 & 150,00 & 150,00 \\
\hline Tomadas e interruptores & 70,00 & 15,00 & 15,00 \\
\hline Vidros para janela & 300,00 & 150,00 & 150,00 \\
\hline Total & $\mathbf{2 . 3 8 0 , 0 0}$ & $\mathbf{1 . 4 1 5 , 0 0}$ & $1.415,00$ \\
\hline
\end{tabular}

\begin{tabular}{|l|l|l|l|}
\hline Material permanente & Ano 1 & Ano 2 & Ano 3 \\
\hline Mini system & $1.000,00$ & 0,00 & 0,00 \\
\hline Notebook & $2.000,00$ & & \\
\hline Cortina & $2.000,00$ & & \\
\hline Impressora multi funcional & 890,00 & & \\
\hline Pen drive 8G & 40,00 & 40,00 & 40,00 \\
\hline Total & $\mathbf{5 . 9 3 0 , 0 0}$ & $\mathbf{4 0 , 0 0}$ & $\mathbf{4 0 , 0 0}$ \\
\hline
\end{tabular}

\section{Despesas correntes}

\begin{tabular}{|l|l|l|l|}
\hline Material de consumo & Ano 1 & Ano 2 & Ano 3 \\
\hline Tonner & 600,00 & 600,00 & 800,00 \\
\hline Tecidos diversos & $1.535,00$ & $2.000,00$ & $2.500,00$ \\
\hline Aviamentos & 800,00 & 800,00 & $1.000,00$ \\
\hline CD-RW & 75,00 & 50,00 & 50,00 \\
\hline Papelaria & $2.000,00$ & $2.000,00$ & $2.200,00$ \\
\hline Total & $\mathbf{5 . 0 1 0 , 0 0}$ & $\mathbf{5 . 4 5 0 , 0 0}$ & $\mathbf{6 . 5 5 0 , 0 0}$ \\
\hline
\end{tabular}


Oficina de Jogos Teatrais

\begin{tabular}{|l|l|l|l|}
\hline Serviços de terceiros & Ano 1 & Ano 2 & Ano 3 \\
\hline Arte Educador 1 & $6.000,00$ & $6.000,00$ & $6.000,00$ \\
\hline Arte Educador 2 & $6.000,00$ & $6.000,00$ & $6.000,00$ \\
\hline Assistente1 & $4.800,00$ & $4.800,00$ & $4.800,00$ \\
\hline Assistente 2 & $4.800,00$ & $4.800,00$ & $4.800,00$ \\
\hline Total & $\mathbf{2 1 . 6 0 0 , 0 0}$ & $\mathbf{2 1 . 6 0 0 , 0 0}$ & $\mathbf{2 1 . 6 0 0 , 0 0}$ \\
\hline
\end{tabular}

\section{Recursos totais}

\begin{tabular}{|l|c|c|c|c|}
\hline Tipo de item & \multicolumn{1}{|l|}{ Ano 1 } & \multicolumn{1}{|l|}{ Ano 2 } & \multicolumn{1}{|l|}{ Ano 3 } & Total \\
\hline Despesas de Capital & $\mathbf{8 . 3 1 0 , 0 0}$ & $1.455,00$ & $1.455,00$ & $11.220,00$ \\
\hline Obras e infraestrutura & $2.380,00$ & $1.415,00$ & $1.415,00$ & \\
\hline Material permanente & $5.930,00$ & 40,00 & 40,00 & \\
\hline Despesas Correntes & $\mathbf{2 6 . 6 1 0 , 0 0}$ & $\mathbf{2 7 . 0 5 0 , 0 0}$ & $\mathbf{2 8 . 1 5 0 , 0 0}$ & $\mathbf{8 1 . 8 1 0 , 0 0}$ \\
\hline Material de consumo & $5.010,00$ & $5.450,00$ & $6.550,00$ & \\
\hline Gastos com locomoção & & & & \\
\hline Serviços de terceiros & $21.600,00$ & $21.600,00$ & $21.600,00$ & \\
\hline Total de recursos do edital & $34.920,00$ & $28.505,00$ & $29.605,00$ & $93.030,00$ \\
\hline Gastos adicionai & & - & - & \\
\hline Recursos totais & $34.920,00$ & $\mathbf{2 8 . 5 0 5 , 0 0}$ & $\mathbf{2 9 . 6 0 5 , 0 0}$ & $\mathbf{9 3 . 0 3 0 , 0 0}$ \\
\hline
\end{tabular}

Categoria em que o projeto se enquadra (com base no valor solicitado ao edital - linha amarela da tabela anterior): Categoria D

\section{Fontes de recursos}

Como citado anteriormente, conteremos com o aporte de recursos pelo parceiro ZF Sachs, para o desenvolvimento da Atividade 2.2. A empresa conta com ônibus para transporte de funcionários que, nos momentos ociosos, podem ser utilizados para o transporte dos integrantes do projeto. Além disso, a aquisição de ingressos para espetáculos pode garantir isenções fiscais para a empresa, baseadas em legislação apropriada. Assim, as vantagens seriam mútuas, garantindo a viabilidade da parceria.

\begin{tabular}{|l|l}
\hline Fonte & Valor
\end{tabular}

Parceiro: ZF Sachs

Recursos totais
$\mathrm{R} \$ 44.000,00$

$R \$ 44.000,00$ 


\section{Contrapartida}

\begin{tabular}{|l|l|l|l|}
\hline Profissionais & $\begin{array}{l}\text { Horas dedicadas } \\
\text { ao projeto }\end{array}$ & Valor médio/hora & $\begin{array}{l}\text { Contrapartida por } \\
\text { profissional }\end{array}$ \\
\hline Diretora Escola & 120 & $30,00 /$ hora & $3.600,00$ \\
\hline Vice -Diretora & 120 & $30,00 /$ hora & $3.600,00$ \\
\hline Coordenadora Pedagógica & 120 & $25,00 /$ hora & $3.000,00$ \\
\hline Coordenadora Pedagógica & 120 & $25,00 /$ hora & $3.000,00$ \\
\hline Professora & 150 & $15,00 /$ hora & $2.2500,00$ \\
\hline Total de contrapartida & 340 & - & $15.450,00$ \\
\hline
\end{tabular}

\section{Conclusão}

O presente Projeto busca solucionar o problema identificado como principal em nossa escola: desenvolver a competência leitora e escritora de maneira plena nos alunos do Ensino Fundamental e Médio. A oferta das "Oficinas de Jogos Teatrais" se apresenta como uma solução, pois desenvolverá nos alunos a disposição para diferentes leituras, discussões, posicionamentos como indivíduos sociais pertencentes a uma comunidade que necessita do seu desenvolvimento pessoal como cidadão para interferir na sociedade em que vive. A forma lúdica proposta para o inicio do projeto, tem a finalidade de envolver o aluno e assim, sem que perceba a intencionalidade, ele passará a desenvolver suas habilidades e essas, depois de já interiorizadas, se expressarão nas suas relações com a escola e com sua aprendizagem. Assim, ao final do processo, teremos alunos com melhores índices de aproveitamento, minimizando os casos de retenção e abandono e melhores preparados para as avaliações a que serão submetidos. Dessa forma, a escola cumprirá seu papel de oferecer educação de qualidade. 